\title{
Abordagem Qualitativa do uso das TDIC na Educação Básica
}

\author{
Ana Amélia Pardini Generoso ${ }^{1}$, João Coelho Neto ${ }^{12}$, Sheila Reinehr ${ }^{2}$, Andreia \\ Malucelli $^{2}$ \\ ${ }^{1}$ Centro de Ciências Humanas e da Educação - Universidade Estadual do Norte do \\ Paraná (UENP) \\ Rua Portugal, 304 - Cornélio Procópio - PR - Brasil \\ ${ }^{2}$ Escola Politécnica - Programa de Pós-Graduação em Informática (PPGIa) - Pontifícia \\ Universidade Católica do Paraná - Curitiba - PR - Brasil \\ melinhapardini@gmail.com, joaocoelho@uenp.edu.br, \\ sheila.reinehr@pucpr.br, malu@ppgia.pucpr.br
}

\begin{abstract}
This paper aims to analyze how teachers of the municipal schools, which obtained a low IDEB in 2007, are using the ICDT after trainings promoted by their own policies and external partnerships, in order to analyze their sense inside the technological training. The exploratory search method was the chosen one, through a semi-structured questionnaire, and the survey was conducted from April to July 2012. After analysis, it was noticed that even after the trainings and the emphasis given by the results to the ICDT, there is still a lack of use in the classroom, because its effectiveness depends on the interest and commitment of the teacher to use them.
\end{abstract}

Resumo: Este artigo tem como objetivo analisar como os professores da rede municipal de ensino, que obtiveram baixo IDEB em 2007, estão utilizando as TDIC após capacitações promovidas por políticas próprias e parcerias externas, visando analisar suas percepções sobre essa formação. Foi realizada uma pesquisa exploratória, sendo a coleta de dados por meio de um questionário semiestruturado, realizada no periodo de abril a julho de 2012. Analisando-se qualitativamente os questionários, percebeu-se que mesmo após as capacitações há uma carência do uso das TDIC em sala de aula, uma vez que seu resultado depende do interesse e compromisso do professor em usálas.

\section{Introdução}

O uso das Tecnologias Digitais da Informação e Comunicação (TDIC), bem como sua integração nas atividades do dia-a-dia, transforma e possibilita as relações humanas, visto que, a expansão das tecnologias e sua conectividade estão cada vez mais intensas e incidindo diretamente no campo educacional, possibilitando novas formas de comunicação e socialização dos saberes [Mallmann et al. 2012].

Ainda, o uso das TDIC acarretam mudanças no âmbito escolar, possibilitando a inovação das práticas pedagógicas, sendo para isso necessário que os professores estejam capacitados a explorar o potencial pedagógico destas tecnologias em sala de 
aula [Sombrio; Rodrigues, 2011]. Com base nessas informações, Coelho Neto et al. (2011, p.989) abordam que:

\begin{abstract}
O uso dos recursos midiáticos, tais como sítios e softwares educacionais, como meio auxiliador no processo de ensino e de aprendizagem é bastante estimulante, tendo que ser planejado e direcionado para o seu bom uso. Entendê-los e dominá-los é o primeiro passo para utilizá-los com sucesso.
\end{abstract}

Desse modo, este trabalho visou dar continuidade em uma pesquisa finalizada em 2010 [Coelho Neto et al. 2011], a qual teve como objetivo capacitar os professores de uma rede municipal de ensino, que obtiveram baixo Índice de Desenvolvimento da Educação Básica (IDEB) em 2007. O período de capacitação desses professores ocorreu entre 2009 e 2010, com oficinas de softwares e sítios educacionais para o processo de ensino e aprendizagem para a Educação Básica.

Essas capacitações foram realizadas a fim de atualizar os professores dessas escolas ao uso dos recursos midiáticos em sala de aula. Com base nessas atribuições, essas capacitações foram divididas em duas etapas: a etapa 1, identificação de como os professores utilizavam as TDIC em sala de aula; e a etapa 2, constituída pelas oficinas.

As atividades da etapa 2 foram divididas em duas sessões: na sessão 1, foi abordada a importância da Informática na Educação e as possibilidades em sala de aula e a sessão 2 foi subdividida em palestras de formação de professores e atividades com o uso de sítios e softwares educacionais. Essas atividades foram realizadas em uma universidade estadual, localizada na mesma região das escolas envolvidas.

Como contribuição destas capacitações, houve o despertar dos professores para o uso das TDIC, favorecendo a utilização desses recursos midiáticos no processo de ensino e de aprendizagem nas séries iniciais, além de que, o conhecimento de tais recursos poderá ainda possibilitar a sua disseminação entre os alunos envolvidos.

Verificando como esses professores estão utilizando as TDIC em sala de aula após as capacitações, este trabalho visou identificar, por meio de uma pesquisa exploratória, se o município deu continuidade as capacitações e analisar qual é a percepção desses professores sobre o uso das tecnologias educacionais para 0 desenvolvimento cognitivo do aluno envolvido.

Dessa forma, este artigo foi dividido em cinco seções: a primeira seção aborda a contextualização e a problemática do tema; na segunda seção a fundamentação teórica é apresentada; na terceira seção é abordado o método de pesquisa; na quarta seção a análise qualitativa dos resultados é apresentada e discutida; e, a quinta seção finaliza este artigo.

\title{
2. Fundamentação Teórica
}

As TDIC na educação podem ser usadas como um instrumento de trabalho, uma vez que, estas representam esse papel em numerosas profissões de natureza técnica e administrativa, além da investigação científica. As novas tecnologias surgem aqui como instrumentos para serem usados livre e criativamente por professores e alunos, na realização das mais diferentes atividades [Ponte 2000].

Além disso, Matos (2008, p.13) aborda que esse processo possui algumas mediações, por isso:

A educação já pressupõe por si só um processo. Tal processo constitui-se primordialmente pela mediação entre sujeito(s) e objeto(s): o sujeito que aprende e algo que se deseja aprender. Esse objeto, a partir de inferências 
semióticas, deverá ter seu significado cultural re(construído), produzindo mudanças perenes no sistema de significação do sujeito. Nesse processo, jamais uma máquina poderia por si só efetuar essa mediação.

Desta forma, o professor, ao propor aos seus alunos a construção da informação por meio das tecnologias, está incentivando e facilitando a relação com a cognição, que pode levar ao conhecimento vivenciado.

Neste instante de criação e elaboração, o aluno busca a superação das dificuldades e problemas que vão surgindo neste processo, assim estes permanecem em contato com diversos conhecimentos possíveis de serem assimilados.

Dessa maneira, o uso das TDIC tem como objetivo auxiliar nas tarefas cotidianas e na aprendizagem, por isso, as TDIC devem ser trabalhadas de forma a melhorar o ambiente no qual estão sendo utilizadas.

Gomes; Gandra (2010, p. 1003) abordam que:

[...] no que diz respeito à aprendizagem por meio do computador, tal afirmativa justifica-se uma vez que as tecnologias utilizadas como suporte para a educação são amplamente valorizadas por favorecerem a interação entre os sujeitos, a elaboração de atividades colaborativas e, por conseguintes, a construção do conhecimento.

Com base nessa construção, ainda há a necessidade de capacitação do uso destes recursos por parte dos professores, para que estes possam ter acesso, pois esses instrumentos estão inseridos em toda a sociedade contemporânea, e seu uso pode ser o diferencial para a educação.

Coelho Neto (2009, p. 40), argumenta que:

[...] o contexto do ensino apresenta a necessidade do uso de maior criatividade, não se limitando à transmissão de conteúdos prontos, de fórmulas a serem memorizadas, mas antes desenvolvendo a capacidade exploratória dos alunos. Com a utilização da Informática na Educação como um auxiliador no processo de ensino e aprendizado, pode-se ministrar conteúdos de modo a utilizar meios de ensino de uma forma mais atraente e acessível.

Por isso, Costa et al. (2011, p. 1469) abordam também que o “[...] professor é o grande agente do processo educacional e precisa estar apto a lidar com as novas tecnologias para utilizá-las a favor da formação de seus alunos".

Desta forma, o uso da tecnologia, além de ser indicada pelas políticas públicas na educação, apresenta-se como uma estratégia para que o professor, em seu trabalho, possa refletir sobre o contexto educacional e social no qual está inserido [Santos et al. 2011].

Nesse sentido, Santos et al. (2011, p. 1501) abordam que é preciso “[...] superar os cursos de capacitação onde o uso das tecnologias se restringe ao acúmulo de fórmulas ou atividades prontas para o professor, ou seja, "treinamento", desvinculado de seu contexto e realidade".

A partir dessa realidade, Rabêlo (2008) reconhece que, para que o professor possa planejar suas atividades utilizando as TDIC, é necessário que esteja capacitado para a elaboração de atividades que possam realmente ser significativas para o aluno e, ainda, estar continuamente em atualização, pois, esse professor precisa entender que o ensino e a aprendizagem são um processo contínuo. 
Mesmo existindo trabalhos dessa temática em informática na educação, observase que os resultados obtidos nessa pesquisa, trazem contribuições no panorama da formação de professores com relação ao uso das TDIC em sala de aula e, ainda, pode-se observar também, de que forma estão sendo utilizados e qual a importância desses para os professores pesquisados.

\section{Método}

Nessa seção apresenta-se a questão da pesquisa, a seleção do método de pesquisa teórica, o instrumento de apoio (questionário semiestruturado) e a condução da pesquisa.

\subsection{Seleção do método de pesquisa}

No desenvolvimento dessa pesquisa, utilizou-se a pesquisa exploratória. Conforme Gil (2007), esta pesquisa tem como objetivo proporcionar maior familiaridade com o tema proposto, a fim de torná-la mais explícita ou para construir hipóteses.

Nesta pesquisa foi utilizado um questionário semiestruturado para obtenção de informações relativas à análise do tema, o qual foi aplicado aos professores dessa pesquisa.

Para Gil (2007 p. 102), o “[...] questionário é um conjunto de questões formuladas a serem respondidas por escrito, por um grupo selecionado à ser pesquisado conforme os objetivos pré estabelecidos", além de, se constituir um meio para obtenção de informações, e que garante o anonimato dos pesquisados sem ter a necessidade de treinamento de pessoal.

O projeto foi realizado com 20 professores de escolas de um munícipio de uma cidade da região sul do Brasil, que tiveram capacitações relativas ao uso da Informática na Educação, no período de 2009-2010, após terem tido um baixo rendimento do IDEB em 2007.

\subsection{Concepção do instrumento de apoio}

Para facilitar a condução das entrevistas, visando obter o máximo de informações em curto período de tempo e otimizando os recursos, optou-se pela utilização de um questionário de apoio. Esse questionário foi semiestruturado, com a finalidade de coletar informações mais detalhadas acerca do cenário estudado. O Quadro 1 apresenta as questões de apoio utilizadas como base para a coleta das informações.

Quadro 1. Questionário para a coleta das informações

\begin{tabular}{|c|c|}
\hline Questão & Objetivo da Questão \\
\hline Q1. Dados do Entrevistado & $\begin{array}{l}\text { Identificar nome, e-mail, gênero e } \\
\text { experiência profissional na área de } \\
\text { magistério. }\end{array}$ \\
\hline Q2. Dados sobre a Instituição & $\begin{array}{l}\text { Identificar nome da Instituição, } \\
\text { município/cidade. }\end{array}$ \\
\hline $\begin{array}{l}\text { Q3. O Município desenvolve alguma } \\
\text { Política de inclusão digital, ou uso das }\end{array}$ & $\begin{array}{l}\text { Identificar se o município possui alguma } \\
\text { política de capacitação de professores ao } \\
\text { uso da tecnologia, visando identificar a }\end{array}$ \\
\hline
\end{tabular}




\begin{tabular}{|l|l|}
\hline TDIC no ensino? & propriedade do tema com o público alvo. \\
\hline $\begin{array}{l}\text { Q4. A escola possui laboratório de } \\
\text { informática? }\end{array}$ & $\begin{array}{l}\text { Identificar se as escolas possuem } \\
\text { laboratórios de informática, a fim de } \\
\text { identificar se esses professores que } \\
\text { obtiveram as capacitações possuem um } \\
\text { local para o uso dos recursos midiáticos } \\
\text { para auxiliar o processo de ensino e } \\
\text { aprendizagem dos alunos. }\end{array}$ \\
\hline $\begin{array}{l}\text { Q5. Descreva de forma sucinta como é } \\
\text { abordado o uso das TDIC em sua aula? }\end{array}$ & $\begin{array}{l}\text { Identificar como estão sendo utilizadas as } \\
\text { TDIC em sala de aula. }\end{array}$ \\
\hline $\begin{array}{l}\text { Q6. Caso não utilize nenhuma TDIC em } \\
\text { sala, descreva o porquê? }\end{array}$ & $\begin{array}{l}\text { Identificar, mesmo que o professor tenha } \\
\text { tido a capacitação, o porquê da não } \\
\text { utilização em sala de aula. }\end{array}$ \\
\hline $\begin{array}{l}\text { Q7. Descreva de forma sucinta como a } \\
\text { tecnologia pode auxiliar no processo de } \\
\text { ensino. }\end{array}$ & $\begin{array}{l}\text { Perceber a importância das tecnologias no } \\
\text { processo de construção do conhecimento } \\
\text { por meio desses professores. }\end{array}$ \\
\hline $\begin{array}{l}\text { Q8. Em sua opinião a tecnologia pode } \\
\text { auxiliar no desenvolvimento cognitivo do } \\
\text { aluno? }\end{array}$ & $\begin{array}{l}\text { Identificar como essa tecnologia pode } \\
\text { auxiliar no desenvolvimento cognitivo do } \\
\text { aprendiz. }\end{array}$ \\
\hline
\end{tabular}

\subsection{Condução da pesquisa}

O contato inicial, feito em abril de 2012, com a Secretaria de Educação (SE) do município, no qual visou apresentar os objetivos da pesquisa, bem como identificar a disponibilidade das escolas para participar.

A partir da aceitação pela SE, esta indicou os possíveis participantes: profissionais que participaram de capacitações no período de 2009 a 2010. A partir da aceitação dos participantes, foi exposto o compromisso ético de manter-se preservada a identidade, ao responder o questionário, ficando caracterizada a participação dos envolvidos nesta pesquisa, e cujos dados seriam objeto de estudo e poderiam ser divulgados em futuras publicações científicas.

A partir dessa explanação, a SE enviou os questionários aos professores selecionados, estipulando assim um prazo de trinta dias para que estes retornassem à secretaria.

Dos 20 questionários enviados para os professores, 16 foram respondidos. Os questionários não respondidos corresponderam aos professores que estavam de licença no período analisado.

Os 16 professores participantes pertencem a rede municipal de ensino, são do gênero feminino, e com uma moda de 06 a 10 anos em experiência no magistério. Para preservar a identidade dos professores, eles foram identificados na análise de dados desta pesquisa por códigos de P1 a P16. Além disso, as questões apresentadas na seção quatro serão identificadas por Q1a Q8. 


\section{Resultados e Discussões}

O primeiro aspecto (Q1) abordado, assim como o segundo (Q2) foram apenas para identificar os dados dos pesquisados, não sendo realizada nenhuma análise específica. Os demais aspectos são discutidos a seguir.

\subsection{Política de Inclusão digital e uso das TDIC no ensino}

O terceiro aspecto tratado (Q3), foi identificar se o município possui alguma política de capacitação de professores ao uso da tecnologia, visando discernir a propriedade do tema com o público alvo.

Observou-se que $68,75 \%$ dos professores disseram que sim e $31,25 \%$ disseram que não. Ressalta-se que a porcentagem que optou pelo "não", identificou que não houve mais capacitações após as oficinas propostas no período de 2009 a 2010. Um dos fatores que pode ter ocorrido com esses $31,25 \%$, é que as capacitações tenham sido realizadas nos períodos de licenças desses professores, visto que, a maioria identificou que o município ofereceu capacitações de alguma forma.

Portanto, além de identificar se houve uma política de inclusão digital, observouse que após essas capacitações, os professores entrevistados abordaram que tiveram mudanças significativas em seu cotidiano, como pode ser observado pelos relatos dos professores nos discursos abaixo:

[...] depois da capacitação ficou mais prático e fácil o acesso ao uso das tecnologias [P1].

[...] aprendi ótimas sugestões de atividades que são utilizadas e desenvolvidas com os alunos [...] as aulas são abordadas com jogos, documentários e filmes [P6].

[...] uso o conhecimento adquirido em sala de aula para favorecer o aprendizado, pois é mais um recurso que pode ser usado para enriquecer suas aulas e motivar seus alunos [P9].

Com isso, foram identificadas mudanças no cotidiano escolar após essas capacitações, auxiliando de forma expressiva o processo de ensino e aprendizagem. Essas abordagens são de suma importância para os professores, pois melhora a perspectiva desse professor em sala de aula, possibilitando inúmeras ações que podem auxiliar no processo educativo. Santos et al. (2011) abordam também a importância de ter políticas públicas para o uso das tecnologias em sala de aula, demostrando uma relação entre o uso desses recursos e a capacitação desse professor a utilizar essas tecnologias no âmbito escolar.

\subsection{TDIC em sala de aula}

No quarto aspecto (Q4) analisado, 100\% dos informantes responderam que as escolas possuem Laboratórios de Informática (LI). Essa questão mostra que esses profissionais possuem condições de utilizar as tecnologias aprendidas para promover o ensino, pois os LI estão funcionando, tendo apenas algumas máquinas sem funcionar, algumas vezes, por falta de profissionais da área de manutenção.

O quinto e sexto aspectos (Q5) e (Q6) identificaram de qual maneira estão sendo utilizadas as TDIC em sala de aula. Neste aspecto $100 \%$ dos professores responderam que utilizam de alguma forma as TDIC em sala de aula. Dessa forma, os professores enfatizam que essa tecnologia pode auxiliar no processo de ensino e da aprendizagem, além da comunicação entre os alunos. 
Fatores que podem ser identificados também pelos seguintes autores Malmann et al. (2012) que abordam a importância do uso das tecnologias e sua conectividade diretamente relacionada ao campo educacional, possibilitando recursos alternativos em sala de aula

\subsection{Tecnologia e ensino}

Para identificar o panorama da situação, o sétimo aspecto tratado (Q7) foi perceber a importância das tecnologias no processo de construção do conhecimento por meio desses professores.

Alguns excertos foram destacados, a fim de analisar como esses instrumentos estão sendo utilizados, além de captar qual a opinião desses professores, tendo em vista que, mesmo tendo baixo IDEB em 2007, houve capacitações posteriores e um aumento significativo desse índice em outro IDEB, resultados identificados pela pesquisa finalizada em 2010. Um excerto referente ao sétimo aspecto pode ser identificado a seguir:

[...] a tecnologia pode auxiliar no processo de ensino, pois algumas atividades realizadas por meio das tecnologias promovem o desenvolvimento e a criatividade do aluno, assim a tecnologia pode sim auxiliar o desenvolvimento cognitivo dos alunos [P1].

Pode-se identificar ainda, em relação ao aspecto Q7, que a tecnologia pode auxiliar no processo de ensino, pois este recurso é atualmente interativo, lúdico e vai ao encontro dos interesses dos alunos, proporcionando aulas dinâmicas e participativas. Outros excertos referentes ao sétimo aspecto podem ser identificados a seguir:

[...] a tecnologia pode auxiliar o desenvolvimento cognitivo dos alunos, pois por meio das TIC os alunos interagem com os conhecimentos diversos, ampliando sua vivência, inteligência e conhecimento do mundo [P2].

[...] depois da capacitação houve alteração no seu dia-a-dia com relação ao uso da Informática na Educação, pois esta pôde fazer pesquisas com os alunos no laboratório de informática [P3].

Além disso, professores mostram algumas adversidades ao uso dessas tecnologias em sala de aula, visto que além da capacitação, outros fatores estão ligados a este processo:

[...] depois da capacitação percebeu que não há assistência técnica para utilizar a tecnologia com os alunos, mesmo possuindo laboratório de Informática na escola, às vezes, são abordadas as TICs, porque apesar de ter laboratório de informática, muitas máquinas necessitam de assistência técnica para funcionar [P4].

Mesmo identificando problemas para o uso, notou-se que a tecnologia auxilia no processo de ensino, pois pode desenvolver alguns conteúdos trabalhados teoricamente, promovendo o desenvolvimento cognitivo dos alunos, pois estes são de uma geração tecnológica.

Foi possível identificar, também, relatos de alguns professores que não estão utilizando os laboratórios de informática, por estarem esperando novas capacitações e melhorias técnicas, tendo em vista a alteração de sistemas em algumas escolas. [P5] argumenta que:

[...] os computadores não recebem assistência técnica e o número de máquinas funcionando é sempre insuficiente impossibilitando o desenvolvimento na área da informática [...] não são abordadas as tecnologias 
porque não houve ainda capacitação para as novas máquinas (Programa PróInfo), às vezes, as Tics são abordadas em aula usando o computador pessoal.

Mesmo com estas dificuldades, aborda-se que a tecnologia pode auxiliar no processo de ensino e possibilita o reforço da aprendizagem, pois, nesse caso, a criança aprende com mais prazer, uma vez que as atividades feitas no computador são lúdicas.

Várias outras abordagens foram identificadas, com base nos relatos:

[...] depois da capacitação ótimas sugestões de atividades foram aprendidas, que são utilizadas e desenvolvidas com os alunos [...] a tecnologia pode auxiliar no processo de ensino ambientando o aluno no mundo digital, assim a tecnologia pode sim auxiliar o desenvolvimento cognitivo dos alunos porque torna seu raciocínio mais ágil [P6].

Para o participante [P6], a tecnologia pode auxiliar no processo de ensino, pois o conhecimento pode ser aprofundado fora da sala de aula e o aluno passa a se expressar mais e com mais segurança.

\title{
4.4. TDIC e desenvolvimento cognitivo
}

O oitavo aspecto tratado (Q8) identificou como as tecnologias podem auxiliar no desenvolvimento cognitivo do aprendiz. Para uma melhor compreensão de como os professores concebem esta abordagem, [P12] identifica que:

\begin{abstract}
[...] a tecnologia pode auxiliar no processo de ensino, pois a informática na educação tende a habilitar o trabalho do docente em pesquisa, e quanto aos alunos a tecnologia aguça o interesse da aprendizagem, assim a tecnologia pode auxiliar no desenvolvimento cognitivo dos alunos, porque atualmente vai de encontro aos anseios dos educadores, promovendo uma aula interativa de maneira lúdica que facilite a aprendizagem.
\end{abstract}

Além disso, a tecnologia pode auxiliar no processo de ensino, pois vem colaborar na própria metodologia do professor, bem como contribuir para um melhor entendimento dos conteúdos programáticos, ajudando assim no desenvolvimento cognitivo dos alunos, porque os recursos audiovisuais contribuem para estimular os alunos em sua aprendizagem. Esses aspectos podem ser identificados também em Coelho Neto (2009), que aborda que com o uso desses recursos, pode-se ministrar conteúdos de modo a utilizar meios de ensino de uma forma mais atraente e acessível.

Para finalizar a análise do oitavo aspecto, [P16] aborda que a tecnologia pode melhorar o processo de ensino de diversas formas, como um recurso diversificado que poderá enriquecer as aulas planejadas, ampliando a capacidade do aluno, além de motivá-lo com técnicas lúdicas.

\section{Conclusão}

Foi possível observar de que forma os professores entrevistados identificam a importância do uso das TDIC nas salas de aula, delineando um panorama nas instituições envolvidas e assim, mapeando as duas grandes questões feitas no início desse trabalho: se o município deu continuidade as capacitações; e identificar a percepção do uso das tecnologias educacionais para o desenvolvimento cognitivo, por meio dos professores envolvidos.

Para a primeira questão, percebeu-se, que além da primeira capacitação do uso das TDIC feita no período de 2009 a 2010, o município promoveu mais ações para que estes professores pudessem estar engajados com o uso das tecnologias em sala de aula. Entretanto, caracterizou-se que ainda há falta de conhecimento a respeito das TDIC, não no sentido de sua importância no processo do conhecimento, ou ainda do auxílio que 
esses instrumentos podem ter em sala de aula, mas sim em como usá-las, quando usá-las e quais usar em determinados conteúdos, para que possam ser de fato eficazes e promover um ambiente propício ao desenvolvimento da cognição dos alunos envolvidos.

Com base nas análises feitas, respondendo a segunda indagação, pode-se identificar por meio dos professores, que o uso das TDIC em sala de aula traz resultados positivos, estimula os alunos a um ambiente que pode ser lúdico e capaz de promover a aprendizagem, desde que seja utilizado de maneira consciente por parte dos professores em sala de aula.

Portanto, ao utilizar as TDIC em qualquer aspecto pedagógico, faz-se necessário que os professores conheçam de fato os instrumentos, pois no seu planejamento estes podem organizar-se de modo a promover ambientes interativos, dinâmicos, problematizadores e significativos, fazendo a diferença no processo de formação em qualquer área do conhecimento.

\section{Referências}

Coelho Neto, J. (2009) "Educação e Informática: Um Estudo Sobre o uso de Ambientes Informatizados com alunos do curso de Pedagogia da Universidade Estadual do Norte do Paraná - Campus de Cornélio Procópio”. Maringá: UEM. 113p. Dissertação de Mestrado.

Coelho Neto, J.; Bernardelli, M. S.; Pessoa, M. P.; Guilhem, M. B.; Malucelli, A.; Reinehr, S. (2011). "O uso das TIC na formação de professores de escolas que obtiveram baixo IDEB”. In: Anais do XXII Simpósio Brasileiro de Informática na Educação (SBIE) e XVII Workshop de Informática na Escola (WIE), Aracaju - SE. p. $988-996$.

Costa, T.; Silva, C.; Rebouças, A.; Alencar, L.; Lopes, E.; Dantas, V.; Souza, F.; Assis, E.; Dantas, J.; Almeida, L.; Andrade, M. V. (2011) "Formação Tecnológica de Professores do Município Tinto: um relato de experiência". In: Anais do XXII Simpósio Brasileiro de Informática na Educação (SBIE) e XVII Workshop de Informática na Escola (WIE), Aracaju - SE. p. 1468-1477.

Gil. A. C. (2007) “Como elaborar projetos de pesquisa”. 4 ed. São Paulo: Atlas.

Gomes, M. A. F; Gandra, A. F. (2010) "Letramento Digital dos Professores dos Anos Iniciais do Ensino Fundamental”. In: Anais do XVI Worshop sobre Informática na Escola (WIE). Belo Horizonte - MG. p. 1001-1010.

Mallmann, E. M; Schneider, D. R.; Teixeira, T. G.; Sales; J. V.; Toebe, I.C.D. (2012) "Fluência Tecnológica dos Tutores em Ambientes Virtuais". Revista Novas Tecnologias na Educação (RENOTE). V.10, no. 1, julho, p.1-10.

Matos, E. S. A (2008) "Revolução da técnica: análise de possibilidades para a educação mediada por computador". In: Anais do XXVIII Congresso da Sociedade Brasileira de Computação - WIE - Workshop sobre Informática na Escola, Belém, PA. p.1118.

Ponte, J. P. (2000) "Tecnologias de informação e comunicação na formação de professores: Que desafios?”. Revista Iberoamericana de Educación. Número 24, Septiembre - Diciembre. 
Rabêlo, E. M. S. (2008) “Capacitação de Professores em Informática Educativa e seus reflexos na Prática Pedagógica". In: Anais do XXVIII Congresso da SBC Workshop sobre Informática na Escola (WIE). Belém do Pará - PA. p. 410-413.

Santos, D. A. P; Schlünzen, E. T. M; Schlünzen Júnior, K. (2011) “Tecnologias Educacionais na Formação em Serviço de Professores: perspectivas para uma escola inclusiva”. In: Anais do XXII Simpósio Brasileiro de Informática na Educação (SBIE) e XVII Workshop de Informática na Escola (WIE), Aracaju - SE. p. 14981506.

Sombrio, C. M.; Rodrigues, A. P. (2011) “O uso das TICs nas salas de recursos TGD”. Revista Novas Tecnologias na Educação (RENOTE). V.9, no. 1, julho, p. 1-11. 